\title{
The effects of hyperoside on apoptosis and the expression of Fas/FasL and survivin in SW579 human thyroid squamous cell carcinoma cell line
}

\author{
ZHENFANG LIU $^{1 *}$, GUODONG LIU ${ }^{1 *}$, XIAOWEI LIU ${ }^{1}$ and SHOUCHAO LI ${ }^{2}$ \\ ${ }^{1}$ Department of General Surgery, Yidu Central Hospital of Weifang, Weifang, Shandong 262500; \\ ${ }^{2}$ Department of General Surgery, Weifang People's Hospital, Weifang, Shandong 261041, P.R. China
}

Received March 1, 2017; Accepted May 29, 2017

DOI: $10.3892 / 01.2017 .6453$

\begin{abstract}
This study investigated the effects of hyperoside on apoptosis of human thyroid squamous cell carcinoma cells (SW579) and measured changes in the expression of known apoptosis regulatory players Fas/FasL and survivin. SW579 cells were treated with increasing concentrations of hyperoside. The cell proliferation inhibition rate was measured by MTT assay. Morphological changes in cells were observed by microscopy. Cell apoptosis was detected by flow cytometry using AV-PI double staining. The normalized expression levels of Fas and FasL mRNAs were detected by reverse transcription quantitative PCR (RT-qPCR), and the expression of the survivin protein was detected by western blotting. Our results showed that hyperoside significantly inhibited the activity of SW579 cells; obvious morphological changes were observed and apoptosis was induced in a dose-dependent manner. Hyperoside was shown to upregulate the expression of Fas and FasL mRNAs and downregulate the expression of the survivin protein. The results suggested that hyperoside can induce the apoptosis of the SW579 human thyroid squamous cell carcinoma cell line, and partially by upregulating the expression of Fas and FasL mRNAs and downregulating the expression of survivin protein in the process of apoptosis. Further studies on the use of hyperoside against cancer cells are required.
\end{abstract}

\section{Introduction}

Thyroid cancer accounts for $30 \%$ of head and neck cancers and its morbidity and mortality rates rank first among the

Correspondence to: Dr Shouchao Li, Department of General Surgery, Weifang People's Hospital, 151 Guangwen Street, Weifang, Shandong 261041, P.R. China

E-mail: las80x@163.com

*Contributed equally

Key words: hyperoside, human thyroid squamous cell carcinoma, SW579, apoptosis, Fas/FasL, survivin endocrine malignancies. In recent years, there has been a significant upward trend in the incidence of thyroid cancer (1). It has been reported that thyroid cancer patients in the United States in 2010 included 33,930 females and 10,740 males, of which 1,690 cases succumbed to the disease (2). Well-differentiated papillary thyroid carcinoma accounted for $80 \%$ of the cases, and the 10 -year survival percentage for those patients was $90 \%$, although $>10 \%$ of patients had recurrences or metastases (3). Once thyroid cancer reaches a late or recurrent level, there is often a poor prognosis, and surgical treatment is not indicated in many of these patients. To make matters worse, the available radiotherapy/chemotherapy has not only poor efficacy, but is also highly toxic and produces side effects. Therefore, it is necessary to find highly efficient and low toxicity drugs to treat thyroid cancers. In recent years, a growing number of studies have turned to natural medicines characterized by their low toxicity, high security and abundant sources. Finding high efficacy, low toxicity antitumor active ingredients in natural medicines has become a target for the drug research and development industries.

Hyperoside, an important active ingredient of Hypericum perforatum L, is a flavonoid glycoside compound (4). Studies have been carried out on the toxicology and pharmacology of hyperoside and related compounds showing low toxicity and few side effects, when used as an antioxidant, analgesic, anti-inflammatory, or to protect the cardiovascular system (5), but there is currently little research on the antitumor activities of these compounds.

The elucidation of the detailed mechanisms of players during apoptosis may have far-reaching effects on the general mechanism of apoptosis and greatly aid in the search of targets for drug design. Fas and its ligand FasL are well-known apoptosis-related cell membrane surface molecules. Survivin is a new member of the family of inhibitors of apoptosis (IAPs) and the most potent inhibitor of apoptosis found so far. Survivin has complex functions including inhibiting apoptosis, promoting cell transformation, participating in cell mitosis, angiogenesis, and drug resistance in tumor cells (6). In this study, a thyroid squamous cell carcinoma cell line was treated with hyperoside, the resulting apoptosis in the cells was quantified and the expression of Fas, FasL and survivin was measured to elucidate possible mechanisms and provide 
a theoretical basis for the clinical use of hyperoside against thyroid cancer.

\section{Materials and methods}

Cell culture. Human thyroid squamous cell carcinoma SW579 cells (Cell Bank of the Chinese Academy of Sciences, Shanghai, China) were cultured in DMEM (Gibco Life Technologies, Carlsbad, CA, USA) in an incubator at $37^{\circ} \mathrm{C}$ with $5 \% \mathrm{CO}_{2}$. Once the cells reached $80 \%$ confluence, the cells were removed with trypsin and dissolved in DMEM (containing $10 \%$ calf serum) to a final concentration of $2 \times 10^{8} / 1$. The cells were counted and seeded in corresponding culture plates for subsequent experiments.

MTT detection of cell proliferation inhibition rate. Cells were treated with hyperoside (Sigma, St. Louis, MO, USA) and the cell viability was detected using the MTT colorimetric assay (Sigma), and the cells were seeded in 96-well plates at a concentration of $1 \times 10^{5} / \mathrm{ml}$ with $100 \mu \mathrm{l}$ DMEM/well. After $24 \mathrm{~h}$, hyperoside was added (to final concentrations of $0,2.5,5,10$ and $20 \mu \mathrm{g} / \mathrm{ml}$, respectively). Five wells were replica-plated for each concentration and the experiment was repeated six times independently. The control group cells were not treated with hyperoside. After incubating the cells at $37^{\circ} \mathrm{C}$ with $5 \% \mathrm{CO}_{2}$ for 24, 48 and $72 \mathrm{~h}$, respectively, $10 \mu \mathrm{l}$ MTT was added into each well to a final concentration of $5 \mathrm{mg} / \mathrm{ml}$, after $4 \mathrm{~h}$, the optical density (OD) at $570 \mathrm{~nm}$ was measured using a microplate reader. The cell inhibition rate was calculated according to the formula: inhibition rate $(\%)=(\mathrm{OD}$ value of the control group - OD value of the experimental group/OD value of the control group) $\mathrm{x} 100 \%$.

Morphological observation. After hyperoside treatment for $24 \mathrm{~h}$ (with $0,5,10$ and $20 \mathrm{mg} / \mathrm{ml}$ hyperoside), any morphological changes were observed and images were captured with an inverted microscope (Nikon, Tokyo, Japan).

Cell apoptosis analysis. SW579 cells in the logarithmic growth phase were seeded in 6-well plates. After $12 \mathrm{~h}$, the cells were treated with $0,5,10$ and $20 \mu \mathrm{g} / \mathrm{ml}$ hyperoside, respectively. After $24 \mathrm{~h}$, the cells were washed three times with PBS, digested with trypsin and then centrifuged. The specific protocol for the Annexin V-FITC apoptosis detection kit (Biyuntian Biotechnology Research Institute, Jiangsu, China) was carried out as per the manufacturer's instructions. Briefly, after centrifugation the cells were resuspended in $0.3 \mathrm{ml}$ of binding buffer. Then, $5 \mu \mathrm{l}$ of Annexin $\mathrm{V}$ and $5 \mu \mathrm{l}$ of PI were added, and the cells were incubated at room temperature in the dark for $15 \mathrm{~min}$. Binding buffer $(0.2 \mathrm{ml})$ was added to each sample and cell apoptosis was detected by flow cytometry (Becton, Dickinson and Company, Franklin Lakes, NJ, USA).

Expression of Fas and FasL mRNAs detected by RT-qPCR. Cells were seeded in 6 -well plates with $1 \times 10^{4}$ cells/well. After $24 \mathrm{~h}$, the supernatant was aspirated and cells were treated with $0,5,10$ and $20 \mu \mathrm{g} / \mathrm{ml}$ hyperoside, respectively. After $24 \mathrm{~h}$, the cells were collected and total RNA was extracted according to the protocol in the RNA extraction kit (Invitrogen Life
Table I. Primer sequences of Fas and FasL.

\begin{tabular}{ll}
\hline Gene & \multicolumn{1}{c}{ Primer sequences } \\
\hline Fas & F: 5'-GGCATCTGGACCCTCCTACCTCTG-3' \\
& R:5'-CCTTGGAGTTGATGTCAGTCACTTGG-3' \\
FasL & F: 5'-GGCCTGTGTCTCCTTGTGAT-3' \\
& R:5'-TGCCAGCTCCTTCTGAAGTA-3' \\
GAPDH & F: 5'-ATGGCACCGTCAAGGCTGAG-3' \\
& R:5'-GCAGTGATGGCATGGACTGT-3' \\
\hline
\end{tabular}

Technologies, Carlsbad, CA, USA). The concentration and purity of total RNA were detected by UV-Vis spectrophotometer (Hitachi, Tokyo, Japan) (A260/A280 >1.8 indicating pure RNA). cDNA was obtained via reverse transcription from RNA and the expression of Fas and FasL mRNAs was detected by RT-PCR based on the instruction of the RT-PCR kit (Invitrogen Life Technologies). Primers were designed by Takara Bio (Dalian, China) (Table I). Reaction conditions were as follows: $94^{\circ} \mathrm{C}$ for $5 \mathrm{~min}$; then $94^{\circ} \mathrm{C}$ for $30 \mathrm{sec}, 57^{\circ} \mathrm{C}$ for $30 \mathrm{sec}, 72^{\circ} \mathrm{C}$ for $30 \mathrm{sec}$, a total of 35 cycles of amplification; and a final elongation at $72^{\circ} \mathrm{C}$ for $5 \mathrm{~min}$. The $\mathrm{Ct}$ value was automatically calculated by software, the $\mathrm{Ct}$ values were all normalized against the abundance of the GAPDH control RNA, and the relative quantification of gene expression was calculated by the $2^{-\Delta \mathrm{Ct}}$ method according to the formula: $\Delta \mathrm{Ct}$ (target gene) $=\mathrm{Ct}$ (target gene) $-\mathrm{Ct}$ (control gene) .

Expression of the survivin protein by western blotting. Cells were seeded in 6-well plates with $10^{4}$ cells/well. After $24 \mathrm{~h}$, the supernatants were aspirated and the cells were treated with $0,5,10$ and $20 \mu \mathrm{g} / \mathrm{ml}$ hyperoside, respectively. After $24 \mathrm{~h}$, the cells were collected and lysed with cell lysis buffer (Biyuntian Biotechnology Research Institute), and then centrifuged for $15 \mathrm{~min}$ at high speed and low temperature. After centrifugation at $10,050 \mathrm{x} \mathrm{g}$ for $15 \mathrm{~min}$ the supernatant containing the soluble fraction was collected. The extracted protein concentrations were determined by BCA kit (Biyuntian Biotechnology Research Institute), $50 \mu \mathrm{g}$ of protein was separated on SDS-PAGE, and the separated protein was transferred to a PVDF membrane. The membrane was incubated in blocking buffer for $1 \mathrm{~h}$ at room temperature and then primary rabbit monoclonal survivin antibody (dilution, 1:500; cat. no. ab76424; Abcam,Cambridge, MA, USA) was added and the membrane was incubated over-night at $4^{\circ} \mathrm{C}$. After washing the membrane with TTBS, the secondary goat anti-rabbit (HRP) IgG antibody (dilution, 1:2,000; cat. no. ab6721; Abcam) was added; and the membrane was incubated at room temperature for $1 \mathrm{~h}$. ECL was then added on the membrane and blots were developed in the dark. Images were recorded with a gel imaging system (Bio-Rad Laboratories, Inc., Hercules, CA, USA), GAPDH was used as the internal reference and grayscale values were analyzed and compared. All the antibodies were purchased from Wuhan Sanying Biotechnology (Wuhan, China).

Statistical analysis. SPSS 17.0 software (IBM Corp., Armonk, NY, USA) was used for statistical analyses. Data are presented 


\section{Hyperoside $(\mu \mathrm{g} / \mathrm{ml})$}

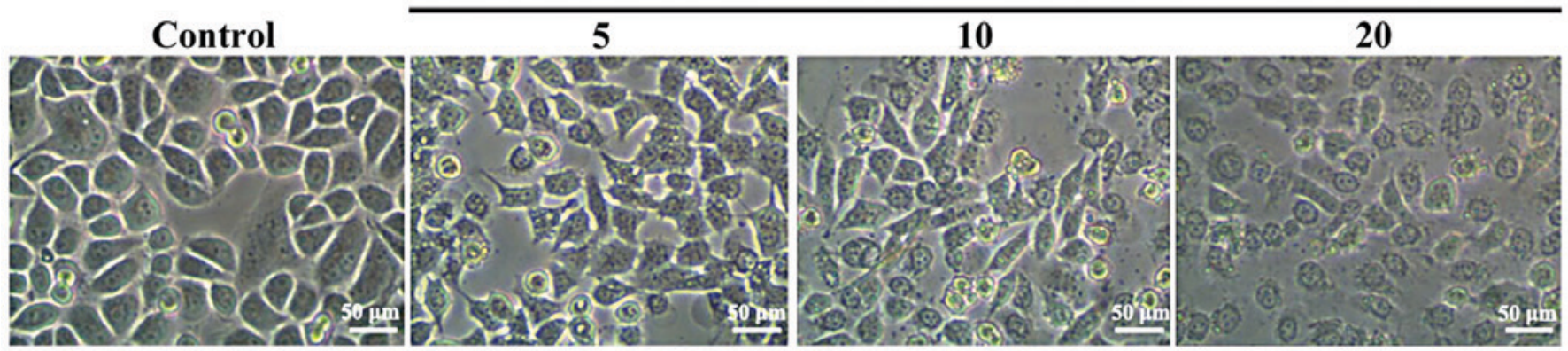

Figure 1. Dose-dependent effects of hyperoside on the morphology of SW579 cells. The effects of different concentrations of hyperoside on the morphology of SW579 cells were observed under an inverted microscope. The changes in cell morphology included cell shrinkage, loose adherence, a decrease in cell number and an increase in the number of cell death.

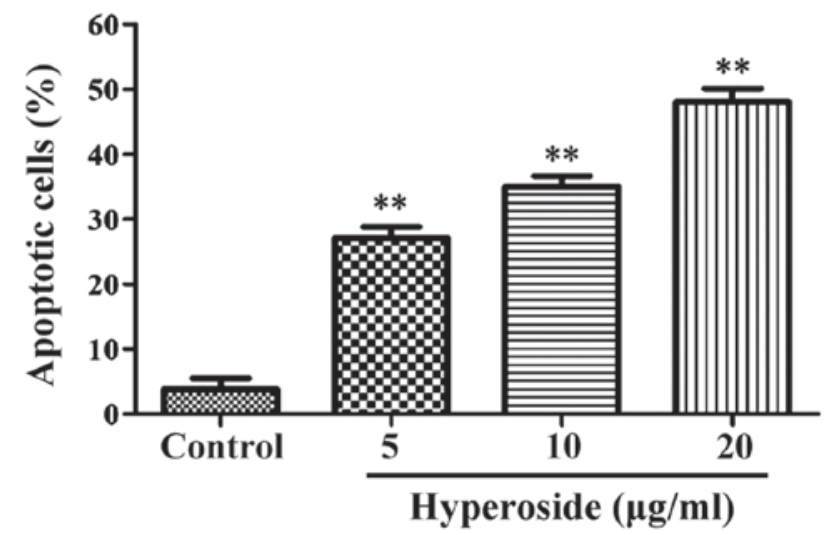

Figure 2. Percentage of apoptotic cells detected by flow cytometry after after treatment with different concentrations of hyperoside. The apoptosis rates of cells were significantly increased after treatment with hyperoside. ${ }^{* *} \mathrm{P}<0.01$ vs. the control group (incubation with $0 \mu \mathrm{g} / \mathrm{ml}$ hyperdoside).

as means \pm standard deviation, and analyzed using one-way ANOVA. Differences with a $\mathrm{P}<0.05$ were considered statistically significant.

\section{Results}

Effect of hyperoside on proliferation inhibition of SW579 cells. After cells were treated with 0, 2.5, 5, 10 and $20 \mu \mathrm{g} / \mathrm{ml}$ hyperoside, the proliferation of SW579 cells was significantly inhibited in all groups. The proliferation inhibition rates were significantly increased with the increase in concentration and time $(\mathrm{P}<0.05)$ showing an obvious dose-dependent mechanism (Table II). However, this study aimed to examine the mechanism of apoptosis, and since $2.5 \mu \mathrm{g} / \mathrm{ml}$ hyperoside did not elicit a clear inhibitory effect on cell proliferation, subsequent experiments were carried out with $5 \mu \mathrm{g} / \mathrm{ml}$ hyperoside as the smallest concentration used. The duration of treatment was $24 \mathrm{~h}$.

Effect of hyperoside on SW579 cell morphology. As shown in Fig. 1, after $24 \mathrm{~h}$ in the presence of 5, 10 and $20 \mu \mathrm{M}$ hyperoside, respectively, the cells underwent significant morphological changes in a dose-dependent manner involving cell shrinkage, loose adherence, a decrease in cell number and an increase in the number of cell death.
Table II. Inhibitory effects of different concentrations of hyperoside on proliferation of SW579 cells (means \pm standard deviation, $\mathrm{n}=30$ ).

\begin{tabular}{lccc}
\hline & \multicolumn{3}{c}{ Cell proliferation inhibition rate $(\%)$} \\
\cline { 2 - 4 } $\begin{array}{l}\text { Concentration } \\
(\mu \mathrm{g} / \mathrm{ml})\end{array}$ & $24 \mathrm{~h}$ & $48 \mathrm{~h}$ & $72 \mathrm{~h}$ \\
\hline Control & & & \\
group $(0)$ & 0 & 0 & 0 \\
2.5 & $20.12 \pm 2.36^{\mathrm{a}}$ & $33.65 \pm 4.23^{\mathrm{a}}$ & $47.92 \pm 5.03^{\mathrm{a}}$ \\
5 & $29.65 \pm 2.86^{\mathrm{a}}$ & $49.53 \pm 7.01^{\mathrm{a}}$ & $66.25 \pm 7.16^{\mathrm{a}}$ \\
10 & $35.37 \pm 3.02^{\mathrm{a}}$ & $63.72 \pm 6.78^{\mathrm{a}}$ & $80.43 \pm 8.41^{\mathrm{a}}$ \\
20 & $46.94 \pm 3.12^{\mathrm{a}}$ & $73.77 \pm 6.25^{\mathrm{a}}$ & $82.83 \pm 9.61^{\mathrm{a}}$ \\
\hline
\end{tabular}

${ }^{\mathrm{a}} \mathrm{P}<0.01$ compared to the control group.

Effect of hyperoside on SW579 cell apoptosis. As shown in Fig. 2, flow cytometry results showed the apoptotic rates as $3.23 \pm 0.52,27.34 \pm 3.18,33.93 \pm 3.78$ and $46.63 \pm 4.75 \%$ in the control 5, 10 and $20 \mu \mathrm{g} / \mathrm{ml}$ hyperoside groups, respectively. Compared with the control group, the apoptotic rates of all the other groups were significantly increased $(\mathrm{P}<0.01)$.

Effect of hyperoside on Fas and FasL mRNA expression. As shown in Fig. 3, the normalized expression of Fas and FasL mRNAs in each hyperoside group was significantly higher than that in the control group, and increased along with the increasing concentrations of hyperoside treatment.

Effect of hyperoside on the expression of survivin protein. As shown in Fig. 4, the expression of survivin protein in each hyperoside group was significantly lower than that in the control group and decreased in a step-wise manner with each increase in the hyperoside concentration applied $(\mathrm{P}<0.01)$.

\section{Discussion}

At present, the high incidence of thyroid cancer in Chinese women has made it one of the most common malignancies $(1,2)$. Furthermore, the incidence and mortality rates of 
A

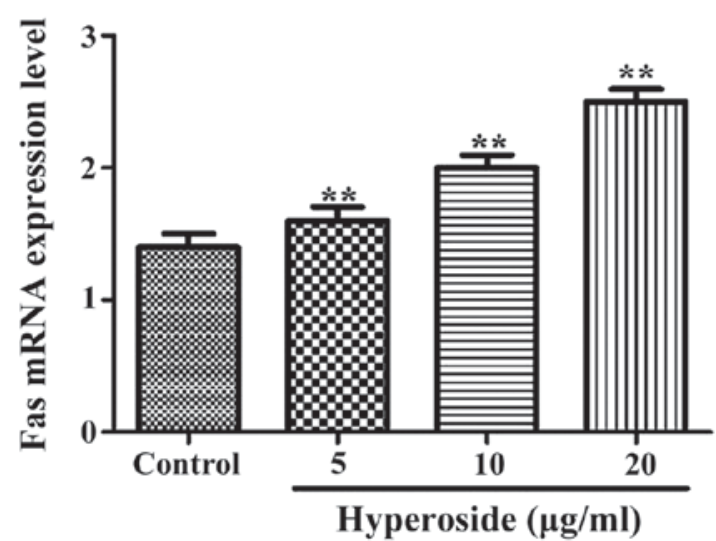

B

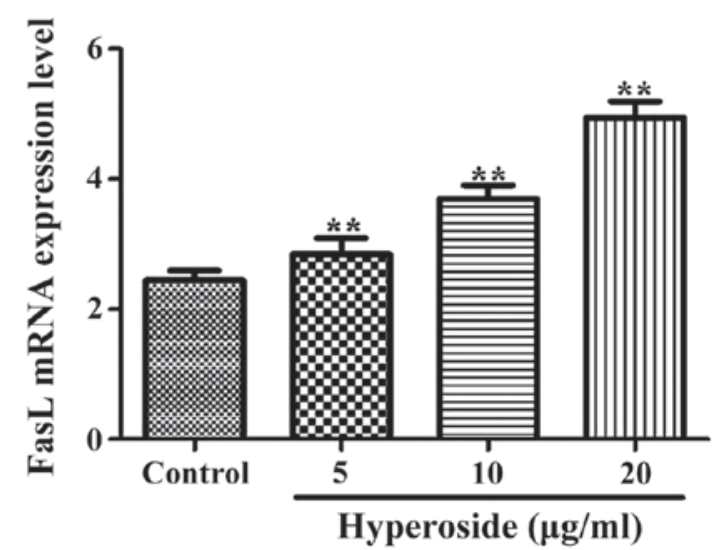

Figure 3. Fas and FasL mRNA levels detected by RT-PCR after treatment with different concentrations of hyperoside. (A) Fas mRNA expression increased significantly with hyperoside concentration. (B) FasL mRNA expression increased significantly with hyperoside concentration. ${ }^{* *} \mathrm{P}<0.01 \mathrm{vs}$. the control group.
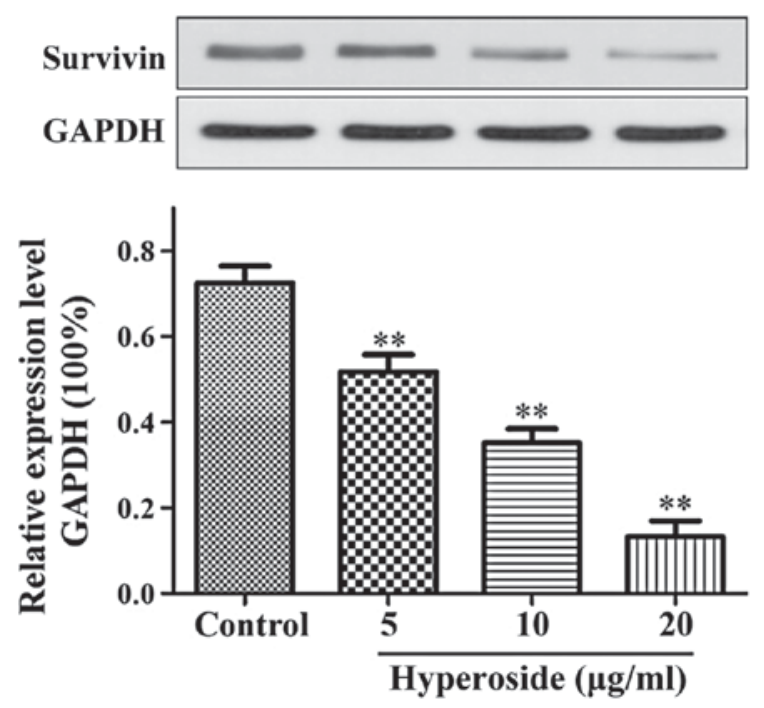

Figure 4. Western blotting showing effects of hyperoside on the expression of survivin protein. After treatment with hyperoside, the expression of survivin protein was significantly inhibited. ${ }^{* *} \mathrm{P}<0.01$ compared to the control group.

thyroid cancer are experiencing upward trends in China (3). The treatment based on chemical drugs is expensive and not very effective and carries with it significant side effects. Therefore, it is necessary to find a highly efficient, low toxicity and affordable treatment. In this study, we explored the effect of hyperoside on the apoptosis of the human thyroid squamous cell carcinoma SW579 cell line and the possible mechanisms leading to it.

Fas is a cell membrane receptor capable of activating intracellular related apoptosis signaling pathways to induce apoptosis when bound to its ligand FasL $(7,8)$. The normal Fas system plays an important role in the homeostasis of organisms, maintaining a dynamic balance between apoptosis and proliferation rates, and its abnormal expression can cause immune system diseases and tumors and affects transplantation immunity (9). The Fas/FasL signaling pathway plays an important role in the process of tumor inhibition and its expression has been found to be downregulated or lost in malignant tumor cells. Furthermore, malignant tumor cells have been shown to downregulate the expression of Fas, while they upregulate the expression of FasL, which would lead to apoptosis induction in tumor-fighting activated $\mathrm{T}$ cells, ultimately favouring the proliferation of tumor cells $(10,11)$. The expression of Fas protein in gastric cancer has been associated with the differentiation status of the cells, whereby poorly differentiated gastric cancer cells express lower quantities of Fas than well-differentiated cancer cells. Furthermore, studies have confirmed that deletion of the Fas gene reduces apoptosis rates and accelerates the proliferation of tumor cells (12). The survivin protein is an important member of the family of apoptosis inhibitors and has the strongest inhibitory effect on apoptosis currently identified (13). Survivin can inhibit apoptosis by interfering with the function of cysteine proteolytic enzymes, and its overexpression is closely related to the poor prognosis of tumors and resistance to chemotherapeutic drugs (14).

In this study, the thyroid squamous cell carcinoma SW579 cells were treated with different concentrations of hyperoside for 24, 48 and $72 \mathrm{~h}$, respectively. Results of MTT assays showed that hyperoside significantly inhibited the activity of the cells treated with hyperoside compared with the activity of cells in the control group. With increasing concentrations and treatment time, the proliferation inhibition rates were significantly increased in a dose-dependent manner. The morphological changes experienced by apoptotic SW579 cells included cell shrinkage, loose adherence, a decrease in cell number and an increase in the number of cell deaths. Additionally, the results of RT-PCR showed the expression levels of Fas and FasL mRNAs increased with increasing hyperoside concentrations suggesting that hyperoside can upregulate the expressions of Fas and FasL and induce apoptosis. Shimada et al (15) found a similar scenario in non-small cell lung cancer cells where the expression of Fas in tumor cells was decreased possibly leading to unlimited cell proliferation (15). Their results support our hypothesis that hyperoside can induce apoptosis of SW579 cells by upregulating the expressions of Fas and FasL mRNAs. Finally, results of western blotting in our study showed that the expression of survivin was inhibited to a higher degree with increasing hyperoside concentrations. Of note, no survivin gene expression has been found in normal thyroid tissues, 
however, survivin expression is active in thyroid cancer cells, and its expression and the degree of malignancy are positively correlated $(16,17)$. Taken together, our findings suggest that hyperoside-induced apoptosis is probably carried out via inhibition of the expression of survivin protein and upregulation of the Fas/FasL system. Our results provide a theoretical basis for the therapeutic effect of hyperoside on thyroid squamous cell carcinoma.

\section{References}

1. Pacini F: How far should we go in the search and treatment of recurrent or persistent lymph node metastases during follow-up of thyroid cancer patients? Eur Thyroid J 2: 145-146, 2013.

2. Siegel R, Naishadham D and Jemal A: Cancer statistics, 2013. CA Cancer J Clin 63: 11-30, 2013.

3. Brehar AC, Brehar FM, Bulgar AC and Dumitrache C: Genetic and epigenetic alterations in differentiated thyroid carcinoma. J Med Life 6: 403-408, 2013.

4. Zou Y, Lu Y and Wei D: Antioxidant activity of a flavonoid-rich extract of Hypericum perforatum L. in vitro. J Agric Food Chem 52: 5032-5039, 2004.

5. Song BW, Ma CG and Xu SY: Hyperin: A new peripheral analgesic agent. Asia Pac J Pharm 3: 1-5, 1998.

6. Waligórska-Stachura J, Jankowska A, Waśko R, Liebert W, Biczysko M, Czarnywojtek A, Baszko-Błaszyk D, Shimek V and Ruchała M: Survivin - prognostic tumor biomarker in human neoplasms - review. Ginekol Pol 83: 537-540, 2012.

7. Myong NH: Tissue microarray analysis of Fas and FasL expressions in human non-small cell lung carcinomas; with reference to the p53 and bcl-2 overexpressions. J Korean Med Sci 20: 770-776, 2005.

8. Chang JS, Hsu YL, Kuo PL, Chiang LC and Lin CC: Upregulation of Fas/Fas ligand-mediated apoptosis by gossypol in an immortalized human alveolar lung cancer cell line. Clin Exp Pharmacol Physiol 31: 716-722, 2004.
9. Ryan AE, Shanahan F, O'Connell J and Houston AM: Fas ligand promotes tumor immune evasion of colon cancer in vivo. Cell Cycle 5: 246-249, 2006.

10. Korkolopoulou P, Saetta AA, Levidou G, Gigelou F, Lazaris A, Thymara I, Scliri M, Bousboukea K, Michalopoulos NV, Apostolikas N, et al: c-FLIP expression in colorectal carcinomas: Association with Fas/FasL expression and prognostic implications. Histopathology 51: 150-156, 2007.

11. Siegel RM, Chan FK, Chun HJ and Lenardo MJ: The multifaceted role of Fas signaling in immune cell homeostasis and autoimmunity. Nat Immunol 1: 469-474, 2000.

12. Morimoto Y, Hizuta A, Ding EX, Ishii T, Hongo T, Fujiwara T, Iwagaki $\mathrm{H}$ and Tanaka N: Functional expression of Fas and Fas ligand on human intestinal intraepithelial lymphocytes. Clin Exp Immunol 116: 84-89, 1999.

13. Shariat SF, Ashfaq R, Karakiewicz PI, Saeedi O, Sagalowsky AI and Lotan Y: Survivin expression is associated with bladder cancer presence, stage, progression, and mortality. Cancer 109: 1106-1113, 2007.

14. Beardmore VA, Ahonen LJ, Gorbsky GJ and Kallio MJ: Survivin dynamics increases at centromeres during $\mathrm{G} 2 / \mathrm{M}$ phase transition and is regulated by microtubule-attachment and Aurora B kinase activity. J Cell Sci 117: 4033-4042, 2004.

15. Shimada T, Nishimura Y, Nishiuma T, Rikitake Y, Hirase T and Yokoyama M: Adenoviral transfer of rho family proteins to lung cancer cells ameliorates cell proliferation and motility and increases apoptotic change. Kobe J Med Sci 53: 125-134, 2007.

16. Olie RA, Simões-Wüst AP, Baumann B, Leech SH, Fabbro D, Stahel RA and Zangemeister-Wittke U: A novel antisense oligonucleotide targeting survivin expression induces apoptosis and sensitizes lung cancer cells to chemotherapy. Cancer Res 60: 2805-2809, 2000.

17. Wu YF, Cao MF, Gao YP, Chen F, Wang T, Zumbika EP and Qian KX: Down-modulation of heat shock protein 70 and up-modulation of Caspase-3 during schisandrin B-induced apoptosis in human hepatoma SMMC-7721 cells. World J Gastroenterol 10: 2944-2948, 2004. 